Research Paper

\title{
Social and economic inequalities in fatal opioid and cocaine related overdoses in Luxembourg: A case-control study
}

\author{
Alain Origer ${ }^{\mathrm{a}, \mathrm{b}, *}$, Etienne Le Bihan ${ }^{\mathrm{b}}$, Michèle Baumann ${ }^{\mathrm{b}}$ \\ a Drug Coordination Office, Ministry of Health, Villa Louvigny, Allée Marconi, L-2120 Luxembourg, Luxembourg \\ ${ }^{\mathrm{b}}$ INtegrative research unit on Social and Individual DEvelopment (INSIDE), University of Luxembourg, Walferdange, Luxembourg
}

\section{A R T I C L E I N F O}

\section{Article history:}

Received 12 December 2013

Received in revised form 18 April 2014

Accepted 27 May 2014

\section{Keywords:}

Substance abuse

Mortality

Drug overdose

Social determinants of health

Socioeconomic inequalities

\begin{abstract}
A B S T R A C T
Background: To investigate social and economic inequalities in fatal overdose cases related to opioid and cocaine use, recorded in Luxembourg between 1994 and 2011.

Methods: Cross-examination of national data from law enforcement and drug use surveillance sources and of forensic evidence in a nested case-control study design. Overdose cases were individually matched with four controls, when available, according to sex, year of birth, drug administration route and duration of drug use. 272 cases vs 1056 controls were analysed. Conditional logistic regression analysis was performed to assess the respective impact of a series of socioeconomic variables.

Results: Being professionally active [OR = 0.66 (95\% CI 0.45-0.99)], reporting salary as main legal income source $[\mathrm{OR}=0.42(95 \% \mathrm{CI} 0.26-0.67)]$ and education attainment higher than primary school $[\mathrm{OR}=0.50$ (95\% CI 0.34-0.73)] revealed to be protective factors, whereas the professional status of the father or legal guardian of victims was not significantly associated to fatal overdoses.

Conclusions: Socioeconomic inequalities in drug users impact on the occurrence of fatal overdoses. Compared to their peers, users of illicit drugs with lower socioeconomic profiles show increased odds of dying from overdose. However, actual and self-referred socioeconomic characteristics of drug users, such as educational attainment and employment, may have a greater predictive value of overdose mortality than the parental socioeconomic status. Education, vocational training and socio-professional reintegration should be part of drug-related mortality prevention policies.
\end{abstract}

(c) 2014 Elsevier B.V. All rights reserved.

\section{Introduction}

Latest estimates from the United Nations Office on Drugs and Crime (UNODC, 2013) and the World Health Organisation (WHO, 2009) refer to 210,000 and 245,000 drug-related deaths per year worldwide and approximately half of these cases are attributed to acute overdoses. Fatal overdose caused by the use of illicit drugs in Europe accounts for an estimated $4 \%$ of premature death in young adults aged $15-39$ years (EMCDDA, 2011).

Risk factors for illicit drug-related overdose have been extensively addressed by scientific research. Numerous studies have investigated demographic, behavioural and drug use related parameters associated to drug-related mortality (Darke \& Zador, 1996; Degenhardt, Bucello, Mathers, Briegleb, \& Ali, 2011; Fischer

\footnotetext{
* Corresponding author is PhD student at: INtegrative research unit on Social and Individual DEvelopment (INSIDE), University of Luxembourg, Walferdange, Luxembourg. Tel.: +352 24785625 ; fax: +352 24795625 .

E-mail address: alain.origer@ms.etat.lu (A. Origer).
}

et al., 2004; Mathers et al., 2013). Research focusing on social and economic determinants appears to be less prevalent, although previous studies have reported associations between fatal overdoses and poor educational attainment (Arias \& Borrell, 1998; Farrell, Neeleman, Griffiths, \& Strang, 1996), unemployment (Harlow, 1990; Pasarin, Borrell, \& Plasencia, 1999), low income (Pasarin et al., 1999; Torralba et al., 1996), poverty status (Jones et al., 2002; Marzuk et al., 1997; Torralba et al., 1996), living in a neighbourhood presenting important income inequalities (Galea et al., 2003; Nandi et al., 2006), homelessness (Langendam, van Brussel, Coutinho, \& van Ameijden, 2001; O'Driscoll et al., 2001), poor psychosocial functioning (Darke \& Zador, 1996), social exclusion and poor social support (Farrell et al., 1996).

Research addressing socioeconomic determinants in drug users and applying matched case-control designs is limited. Davoli et al. (1993) published a study that investigated risk factors for drug overdose mortality, including 81 cases and 324 controls, matched on sex and year of birth and found no association with the educational status of victims. Galea et al. (2003) applied a multilevel case-control study including 725 accidental overdose deaths 
(cases) and 453 accidental deaths due to other causes (controls) in various neighbourhoods in New York City. Their results showed increased odds of dying from overdose in neighbourhoods with unequal income distribution.

Social and economic conditions shape risk behaviours and the health of drug users as they impact on drug use patterns and affect the availability of resources and access to social welfare systems (Galea \& Vlahov, 2002). Nonetheless, fatal overdoses are avoidable to a large extend (Sporer, 2003). Our objective is to assess the impact social and economic parameters may have on the occurrence of fatal overdoses caused by the use of illicit drugs. Our findings should thus contribute to improve knowledge on the pathways that may lead to overdose incidents and to reduce their occurrence and consequences by implementing evidence-based public health and social policies.

Overall characteristics of national fatal overdose victims as well as differences in risk factors according to gender were described previously (Origer, Lopes da Costa, \& Baumann, 2013). As far as problem drug use is concerned, injecting heroin associated to polydrug use is the predominant consumption pattern observed nationally. Free outpatient and reimbursed inpatient and substitution treatment options are available throughout the country and, since 2005, a supervised drug consumption room is being operational in Luxembourg-City besides harm reduction services implemented regionally.

\section{Methods}

\section{Case definition, study design and participants}

In the present study, a fatal overdose case is defined as an intentional or unintentional death for which an acute adverse reaction after the recent use of products containing opioids and/or cocaine is reported as the primary cause of death in the light of toxicological and forensic evidence. Concomitant use of other substances is not an exclusion criterion if the use of opioids and/or cocaine is reported as the primary cause of death by national forensic authorities.

A nested case-control study design was chosen. Cases are defined as victims of a fatal overdose having occurred in Luxembourg between 1994 and 2011. Matched controls refer to persons indexed by the epidemiological surveillance system on drug users in contact with national services (RELIS). Cases were matched with four controls, on sex, year of birth, drug administration route and duration of drug use. Previous research has shown that matching more than four controls with each case does not significantly add statistical power to the analysis (Cai \& Zheng, 2012; Ury, 1975). Controls were never matched to more than one case and deceased users were excluded from the RELIS database in order to avoid that they were matched with cases.

Matching variables are defined as follows:

- Sex (male, female).

- Year of birth (in case no perfect match was available, a difference of one year more or less between the case and controls was accepted).

- Route of administration (injecting drug use, non-injecting drug use).

- Duration of illicit drug use (matching according to duration of drug use is an essential condition to avoid the selection bias of selective survival. Risk exposure parameters of cases and controls were set to be comparable and in case no perfect match could be found, controls with the closest duration of drug use were chosen).

\section{Data sources}

The following data sources have been cross-examined in order to complete victims' profiles, drug use patterns and life histories:

\section{Drug misuse surveillance data}

The national drug monitoring system (RELIS) is operated by the Luxembourg focal point of the European Monitoring Centre on Drugs and Drug Addiction (EMCDDA) and indexes drug-related contacts with both, drug demand and drug supply reduction institutions in a single and integrated database. The RELIS network includes all national psychiatric departments of general hospitals, specialised in- and outpatient drug care services including substitution treatment offers, harm reduction services, prisons and special drug law enforcement agencies.

Indexed drug users are digitally anonymised by means of an encryption algorithm approved by the National Commission on Data Protection. The thus obtained unique attribution code allows respondents' recognition within single and between multiple data sources. The RELIS data protocol includes routine items on sociodemographics, educational, socioeconomic and health status, drug use histories and patterns, treatment records and contacts with the penal system.

\section{Forensic evidence}

In case of a suspicious death case, the public prosecutor's office orders a toxicological investigation and an autopsy of the victim. The forensic department of the National Laboratory of Health (LNH) reports drug-related death cases also to the Ministry of Health for public health surveillance and statistical purposes. Forensic reports contain data on substances detected in the victims, physical aspects as well as an assessment of the association of detected substances and the occurrence of death. Autopsy reports also contain contextual information and elements of life history. Toxicological reports have been anonymised and made available to the research team by LNH, following the authorisation of the Public Prosecutors Office.

\section{National law enforcement records of fatal overdose cases}

National judicial police authorities exhaustively list overdose deaths occurring on the national territory after forensic confirmation. Toxicological evidence and related police reports are compiled for each case.

Cross examination of data sources was possible as RELIS codes have been calculated and attributed to all overdose victims, previously de-identified. Since persons included in the national RELIS database or in the police overdose record are anonymised by the same coding routine, matching cases could be reliably detected. Furthermore, toxicological and autopsy reports were attributed to respective cases by using date of birth and date of death of victims.

\section{Statistical methods}

In order to account for missing values, we performed multiple imputation using the fully conditional specification approach (van Buuren, 2007) on the entire data set and generated 10 imputation data sets. Statistical tests were performed on both, original data (with missing values) and imputed data sets in order to assess the extent to which results converge.

Conditional logistic regression analysis, as recommended for case-control data sets (Breslow \& Day, 1980; Langholz \& Goldstein, 2001), was performed on the entire study sample in order to assess the respective impact of the following explanatory variables on the occurrence of fatal overdoses: 
Table 1

Mean values of matching and explanatory variables.

\begin{tabular}{|c|c|c|c|c|}
\hline \multirow{2}{*}{$\begin{array}{l}\text { Matching variables } \\
\text { Sex }\end{array}$} & \multirow[t]{2}{*}{$\begin{array}{l}\text { Victims (cases) } \\
(n=272)\end{array}$} & \multicolumn{2}{|c|}{$\begin{array}{l}\text { Controls } \\
(n=1056)\end{array}$} & $\begin{array}{l}\text { Total } \\
(N=1328)\end{array}$ \\
\hline & & & & \\
\hline Male & $81 \%$ & $81.6 \%$ & & $81.3 \%$ \\
\hline Female & $19 \%$ & \multicolumn{2}{|c|}{$18.4 \%$} & $18.7 \%$ \\
\hline Mean year of birth & 1971 & \multicolumn{2}{|c|}{1971} & 1971 \\
\hline Injecting drug use & $91.4 \%$ & \multicolumn{2}{|c|}{$91.1 \%$} & $91.2 \%$ \\
\hline Mean duration of illicit drug use & 15.9 years & \multicolumn{2}{|c|}{15.8 years } & 15.9 years \\
\hline Explanatory variables & \multicolumn{2}{|c|}{ Victims (cases) } & Controls & Total \\
\hline \multicolumn{5}{|l|}{ Occupational status } \\
\hline Employed & \multicolumn{2}{|l|}{$23.3 \%$} & $42.3 \%$ & $39.0 \%$ \\
\hline Unemployed & $76.7 \%$ & \multicolumn{2}{|r|}{$57.7 \%$} & $61.0 \%$ \\
\hline \multicolumn{5}{|l|}{ Main income source } \\
\hline Salary of legal origin & \multicolumn{2}{|l|}{$17.0 \%$} & $44.0 \%$ & $39.4 \%$ \\
\hline Other income & $83.0 \%$ & \multicolumn{2}{|r|}{$56.0 \%$} & $60.6 \%$ \\
\hline \multicolumn{5}{|l|}{ Educational attainment } \\
\hline Primary school degree & $78.6 \%$ & \multicolumn{2}{|r|}{$62.1 \%$} & $64.8 \%$ \\
\hline Secondary school degree: & $20.4 \%$ & \multicolumn{2}{|r|}{$37.9 \%$} & $35.0 \%$ \\
\hline High school/university degree & $1.0 \%$ & \multicolumn{2}{|r|}{$0.0 \%$} & $0.2 \%$ \\
\hline \multicolumn{5}{|c|}{ Professional status of father or legal guardian } \\
\hline Unqualified manual worker & $26.1 \%$ & & $27.5 \%$ & $27.2 \%$ \\
\hline Qualified manual worker & $37.0 \%$ & & $32.2 \%$ & $33.1 \%$ \\
\hline White collar & $20.1 \%$ & & $22.6 \%$ & $22.1 \%$ \\
\hline Intermediate occupation & $2.7 \%$ & & $5.5 \%$ & $5.0 \%$ \\
\hline Manager-intellectual profession & $2.2 \%$ & & $3.9 \%$ & $3.6 \%$ \\
\hline Self-employed & $12.0 \%$ & & $8.3 \%$ & $9.0 \%$ \\
\hline
\end{tabular}

- Professional status of father or legal guardian according to INSEE (Institut National de la statistique et des études économiques [National Institute of Statistics and Economic Studies] (INSEE), 2009): unqualified manual worker, qualified manual worker, white collar, Intermediate occupation, manager-intellectual profession, self-employed).

- Professional activity/employment: (yes, no).

- Legal income, salary (yes, no).

- Educational attainment (primary/elementary school degree, secondary school degree, high school/university degree).

Odds ratios (OR) with 95\% confidence intervals were calculated. Statistical analysis was conducted using SPSS version 21.0.

\section{Results}

Our sample was composed of 1328 persons including 272 fatal overdose cases and 1056 controls. Six cases had to be excluded from the sample as no matching controls were found. For 3, 4 and 15 cases, respectively 1,2 or 3 controls only could be matched. Eighty-one percent of controls matched cases for all matching variables, $4 \%$ were closest matches ( \pm 1 year) for date of birth, $13 \%$ for duration of drug use career and $2 \%$ for both matching variables. The distribution of missing values for predictor variables is as follows: professional status of father or legal guardian (26.5\%), main income source (13.7\%), educational attainment (10.7\%) and occupational status (6.9\%)

Table 1 displays values of matching variables of the total study population, of overdose victims and controls separately. As cases and controls were matched on the referred variables, respective mean values do converge. A majority of overdose victims were male and injecting drug users. The mean duration of drug use reached approximately 16 years.

As can be seen in Table 2, professional activity/employment $[\mathrm{OR}=0.66$ (95\% CI $0.45-0.99)]$, reporting salary as main legal income source $[\mathrm{OR}=0.42(95 \% \mathrm{CI} \quad 0.26-0.67)$, and educational attainment higher than primary school $[\mathrm{OR}=0.50(95 \% \mathrm{CI}$ $0.34-0.73)$ ], revealed to be protective factors of fatal overdoses. The professional status of the father or legal guardian of victims is not
Table 2

Odds ratios (OR) (CI: 95\%) of explanatory variables as determined by conditional logistic regression on imputed data.

\begin{tabular}{lccc}
\hline Predictor & $\mathrm{OR}^{\mathrm{a}}$ & $95 \% \mathrm{CI}^{\mathrm{b}}$ & $p$ \\
\hline $\begin{array}{l}\text { Occupational status } \\
\quad \text { Professional }\end{array}$ & 0.66 & $0.45-0.99$ & .042 \\
$\quad$ activity/employment vs & & & \\
$\quad$ professional inactivity & & & \\
Main income source & 0.42 & $0.26-0.67$ & $<.001$ \\
$\quad$ Salary of legal origin vs other & & & \\
$\quad$ income source & & & \\
Educational attainment & & & \\
$\quad$ Secondary school degree vs & 0.50 & $0.34-0.73$ & \\
$\quad$ primary/elementary school & & & \\
$\quad$ degree & & & .543 \\
Professional status of father or legal guardian & & .628 \\
$\quad$ Qualified manual worker & 1.16 & $0.72-1.85$ & .192 \\
$\quad$ White collar & 0.89 & $0.54-1.45$ & .472 \\
$\quad$ Intermediate occupation & 0.52 & $0.20-1.39$ & .411 \\
$\quad$ Manager-intellectual profession & 0.66 & $0.22-2.04$ & \\
$\quad$ Self-employed & 1.31 & $0.69-2.47$ & \\
$\quad$ vs unqualified manual worker & & & \\
\hline
\end{tabular}

a Odds ratio.

b Confidence interval.

c Only two fatal overdose cases and none of the control cases had a high school/university degree. Therefore this category had to be excluded from the analysis.

significantly associated to overdose deaths. Results of conditional logistic regression analysis run on original data and on imputed data converged for all explanatory variables and categories.

\section{Discussion}

Key results

We studied the relation between socioeconomic factors and the occurrence of fatal overdoses by analysing respective cases registered between 1994 and 2011 in Luxembourg.

Our results suggest that social and economic factors impact on the occurrence of fatal overdoses, but not necessarily all factors and not necessarily in the same way. Unemployment, unstable/illegal income and lower educational attainment of victims were associated to overdose mortality, whereas the professional status of their parental authority was not at any level. In the light of these outcomes, one may speculate that socioeconomic disadvantages act on individual level, according to their impact on daily life rather than to follow the paths of intergenerational determinism.

In terms of prevention, this is a relevant finding as it challenges the idea that drug use and its negative outcomes tend to develop on the grounds of family settings marked by social disadvantages, reminding the complex and still controversial nature of this question (Galea, Nandi, \& Vlahov, 2004; Humensky, 2010; Patrick, Wightman, Schoeni, \& Schulenberg, 2012; Sutherland, 2012). Moreover, individual achievements such as educational attainments and employment seem to be far more predictive with regard to fatally ending drug use careers since they impact on everyday life quality. Confronting our findings with evidence from other studies on the link between general mental health and employment or work commitment, (Baumann, Meyers, Le Bihan, \& Houssemand, 2008; Murphy \& Athanasou, 1999) one could expect that rehabilitation programmes, which include education, professional training and occupational re-integration may contribute to a certain extend to reducing drug-related mortality. Thus, integrating these measures in harm reduction programmes and developing adequate tools for early recognition of overdose risk contexts could potentially save lives, generate years of life without major impairments and enhance evidence based prevention policies. 


\section{Added value and generalisability}

Studies on the association between education or employment and fatal overdoses in reference to the general population (Arias \& Borrell, 1998; Pasarin et al., 1999) and both, fatal and nonfatal overdoses in cross-sectional settings (Bergenstrom et al., 2008; Siegler, Tuazon, O’Brien, \& Paone, 2014) have provided valuable outcomes in recent years. However, case-control studies addressing multiple socioeconomic parameters in fatal overdose victims are still scarce. Furthermore, previous research has shown no association between parental socioeconomic status and the initiation of substance abuse in children (Sutherland, 2012), but we could find none investigating the link between parental status and fatal overdose of descendants.

Also, our study included, probably for the first time, drug administration route and duration of drug use as matching variables in order to take due account of the risk exposition of both, cases and controls. This methodological aspect as well as the large number of cases and controls and the cross-analysis of data from different data sources and settings should add validity to our findings.

\section{Limitations and further research}

The scarcity of studies on socioeconomic determinants of fatal overdoses may stem from the fact that data on parameters such as education, income, financial wealth and professional activity of both, parents and users are difficult to gather. These aspects are often not included in routine registration or monitoring protocols or documented only by incomplete datasets.

We dealt with missing data by means of a multiple imputations' procedure. Although results from original and imputed data did converge, a lower rate of missing data would have been beneficial to the reliability of our findings. A prospective cohort design may allow collecting more descriptive data especially with regards to family contexts and the socioeconomic status of parents.

Given that overdose cases were accessed from forensic sources, while controls were selected from the national drug monitoring system (RELIS), a possible selection bias cannot be excluded. However, we found that $85.3 \%$ of overdose cases were also recorded in the RELIS database. Furthermore, we compared the distribution of the gender, age, educational levels, employment status, depths of victims and the professional status of their father or legal guardian and found no significant differences between cases recorded in RELIS and those that were not.

We measured the respective impact of social and economic factors but not the possible interactions in terms of cumulative protective and risk effects. A further important step in understanding the dynamic by which these parameters impact on health outcomes, and on overdoses in particular, could be made by investigating the existence of a social gradient in fatal overdose cases. In other words, by addressing the question whether the odds of a fatal overdose incident increase proportionally to the accumulation of social and economic disadvantages. This could be achieved by means of an indicator or index that includes social and economic parameters according to their respective weight of explanatory power. This indicator should build upon social and economic determinants as well as their interactions and, as such, might be used as a risk assessment tool for drug overdoses.

\section{Acknowledgements}

Thanks are due to the Department of Toxicology of the National Laboratory of Health for providing forensic data and the staff of the EMCDDA Focal Point Luxembourg/CRP-Santé for its relentless efforts to ensure and maintain the quality of data provided by the national RELIS surveillance system and to all participating agencies.

Conflicts of interest: None.

\section{References}

Arias, L. C., \& Borrell, C. (1998). Mortality inequalities according to education in the City of Barcelona. Medicina Clinica, 110, 161-166.

Baumann, M., Meyers, R., Le Bihan, E., \& Houssemand, C. (2008). Mental health (GHQ12; CES-D) and attitudes towards the value of work among inmates of a semi-open prison and the long-term unemployed in Luxembourg. BMC Public Health, 8, 214

Bergenstrom, A., Quan, V. M., Van Nam, L., McClausland, K., Thuoc, N. P., Celentano, D., et al. (2008). A cross-sectional study on prevalence of non-fatal drug overdose and associated risk characteristics among out-of-treatment injecting drug users in North Vietnam. Substance Use and Misuse, 43, 73-84.

Breslow, N. E., \& Day, N. E. (1980). Statistical methods in cancer research. Volume I The analysis of case-control studies. IARC Scientific Publications.

Cai, T., \& Zheng, Y. (2012). Evaluating prognostic accuracy of biomarkers in nested case-control studies. Biostatistics, 13, 89-100.

Darke, S., \& Zador, D. (1996). Fatal heroin 'overdose': A review. Addiction, 91 1765-1772.

Davoli, M., Perucci, C. A., Forastiere, F., Doyle, P., Rapiti, E., Zaccarelli, M., et al. (1993). Risk factors for overdose mortality: A case-control study within a cohort of intravenous drug users. International Journal of Epidemiology, 22, 273-277.

Degenhardt, J., Bucello, C., Mathers, B., Briegleb, C., \& Ali, H. (2011). Mortality among regular or dependant users of heroin and other opiods: A systematic review and meta-analysis of cohort studies. Addiction, 106, 32-51.

EMCDDA. (2011). Mortality related to drug use in Europe: Public health implications. Lisbon: EMCDDA

Farrell, M., Neeleman, J., Griffiths, P., \& Strang, J. (1996). Suicide and overdose among opiate addicts. Addiction, 91, 321-323.

Fischer, B., Brissette, S., Brochu, S., Bruneau, J., el-Guebaly, N., Noel, L., et al. (2004). Determinants of overdose incidents among illicit opioid users in 5 Canadian cities. CMAJ, 171, 235-239.

Galea, S., Ahern, J., Vlahov, D., Coffin, P. O., Fuller, C., Leon, A. C., et al. (2003). Income distribution and risk of fatal drug overdose in New York City neighborhoods. Drug and Alcohol Dependence, 70, 139-148.

Galea, S., Nandi, A., \& Vlahov, D. (2004). The social epidemiology of substance use. Epidemiologic Reviews, 26, 36-52.

Galea, S., \& Vlahov, D. (2002). Social determinants and the health of drug users: Socioeconomic status, homelessness, and incarceration. Public Health Reports, 117(Suppl. 1), S135-S145.

Harlow, K. C. (1990). Patterns of rates of mortality from narcotics and cocaine overdose in Texas, 1976-87. Public Health Reports, 105, 455-462.

Humensky, J. L. (2010). Are adolescents with high socioeconomic status more likely to engage in alcohol and illicit drug use in early adulthood? Substance Abuse Treatment, Prevention, and Policy, 5, 19.

Institut National de la statistique et des études économiques [National Institute of Statistics and Economic Studies] (INSEE). (2009). P.-N.-., liste des catégories socioprofessionelles agréée [Agregated occupational categories]. INSEE.

Jones, R., Gruer, L., Gilchrist, G., Seymour, A., Black, M., \& Oliver, J. (2002). Recent contact with health and social services by drug misusers in Glasgow who died of a fatal overdose in 1999. Addiction, 97, 1517-1522.

Langendam, M. W., van Brussel, G. H., Coutinho, R. A., \& van Ameijden, E. J. (2001). The impact of harm-reduction-based methadone treatment on mortality among heroin users. American Journal of Public Health, 91, 774-780.

Langholz, B., \& Goldstein, L. (2001). Conditional logistic analysis of case-control studies with complex sampling. Biostatistics, 2, 63-84.

Marzuk, P. M., Tardiff, K., Leon, A. C., Hirsch, C. S., Stajic, M., Portera, L., et al. (1997) Poverty and fatal accidental drug overdoses of cocaine and opiates in New York City: An ecological study. American Journal of Drug and Alcohol Abuse, 23, 221-228.

Mathers, B. M., Degenhardt, L., Bucello, C., Lemon, J., Wiessing, L., \& Hickman, M (2013). Mortality among people who inject drugs: A systematic review and meta-analysis. Bulletin of the World Health Organization, 91, 102-123.

Murphy, G., \& Athanasou, J. (1999). The effect of unemployment on mental health. Journal of Occupational and Organizational Psychology, 72, 83-99.

Nandi, A., Galea, S., Ahern, J., Bucciarelli, A., Vlahov, D., \& Tardiff, K. (2006). What explains the association between neighborhood-level income inequality and the risk of fatal overdose in New York City? Social Science and Medicine, 63, 662-674.

O'Driscoll, P. T., McGough, J., Hagan, H., Thiede, H., Critchlow, C., \& Alexander, E. R (2001). Predictors of accidental fatal drug overdose among a cohort of injection drug users. American Journal of Public Health, 91, 984-987.

Origer, A., Lopes da Costa, S., \& Baumann, M. (2013). Opiate- and cocaine-related fatal overdoses in Luxembourg from 1985 to 2011: A study on gender differences. European Addiction Research, 20, 87-93.

Pasarin, M., Borrell, C., \& Plasencia, A. (1999). Two patterns of social inequalities in mortality in Barcelona, Spain? Gaceta Sanitaria, 13, 431-440.

Patrick, M. E., Wightman, P., Schoeni, R. F., \& Schulenberg, J. E. (2012). Socioeconomic status and substance use among young adults: A comparison across constructs and drugs. Journal of Studies on Alcohol and Drugs, 73, 772-782. 
Siegler, A., Tuazon, E., O'Brien, D. B., \& Paone, D. (2014). Unintentional opioid overdose deaths in New York City, 2005-2010: A place-based approach to reduce risk. International Journal of Drug Policy, http://dx.doi.org/10.1016/ j.drogpo2013.10.015

Sporer, K. A. (2003). Strategies for preventing heroin overdose. BMJ, 326, 442-444.

Sutherland, A. (2012). Is parental socio-economic status related to the initiation of substance abuse by young people in an English city? An event history analysis. Social Science and Medicine, 74, 1053-1061.

Torralba, L., Brugal, M. T., Villalbi, J. R., Tortosa, M. T., Toribio, A., \& Valverde, J. L. (1996). Mortality due to acute adverse drug reactions: Opiates and cocaine in Barcelona, 1989-93. Addiction, 91, 419-426.
UNODC. (2013). World Drug Report 2013 (United Nations Publication). Vienna: UNODC.

Ury, H. K. (1975). Efficiency of case-control studies with multiple controls per case: Continuous or dichotomous data. Biometrics, 31, 643-649.

van Buuren, S. (2007). Multiple imputation of discrete and continuous data by fully conditional specification. Statistical Methods in Medical Research, 16, 219-242.

WHO. (2009). Global health risks: Mortality and burden of disease attributable to selected major risks. Geneva: WHO. 